\title{
Women Safety Ensurance Device
}

\author{
R.Balamurugan ${ }^{1}$, T.Muruganantham ${ }^{2}$ \\ Assistant Professor, ECE, K.Ramakrishnan College of Engineering, Trichy, India ${ }^{1,2}$
}

\begin{abstract}
In this system provides a Security solution that creates a sense of safety among women. The device can be activated with just a push of a button the GPS connected to the device tracks the current location coordinates of victim and the GSM instantly sends out emergency message to the concerned family members and also the device starts to record any conversation happening there. The device is provided with a stun gun which can provide selfsecurity to women .In this paper we intend to design partial wearable and portable system for the safety of the women.
\end{abstract}

Keywords: RFID, GPS tracking, GSM voice IC, voice recorder

\section{INTRODUCTION}

In recent years, acts of assault against women are rising at a menacing rate. With escalation of female employees in industries and other sectors of the commercial market, it is now becoming a necessity for females to travel at late hours and visit distant and isolated locations as a part of their work regime.Defence isn't the only measure that can suffice against this increasing abuse.A security solution that creates a sense of safety among women needs to be devised. There is thus, a need of simpler safety solution that can be activated and implement such a system in the form of as simply as by pressing a switch and can instantly send out alerts to the near ones of and also to record any conversation happening in that situation, intend to design partial wearable and portable system for the safety of the women.

\section{EXISTING SYSTEM}

The design and development of wearable sensors systems for health monitoring has gained lots of attention in the scientific community and industry during last years. Mainly motivated by increasing healthcare costs and propelled by recent technological advancement. with increasing the atrocities on women and children arises the need of an advanced system to serve the purpose of alerting someone for help. the safety of women is concern of increasing urgency in India and other countries. The primary issue in the handling of these cases by the police lies in constraints preventing them from responding quickly to call of distress.

\section{PROPOSED SYSTEM}

The pic microcontroller which forms the heart of the project plays an important role in establishing communication between input and output. The system is turned $\mathrm{ON}$ and when switch is pressed in instances of attack, manually by the woman. This switch triggers a microcontroller that activates an on-body shock circuit and also the buzzer starts to produce annoying sound.

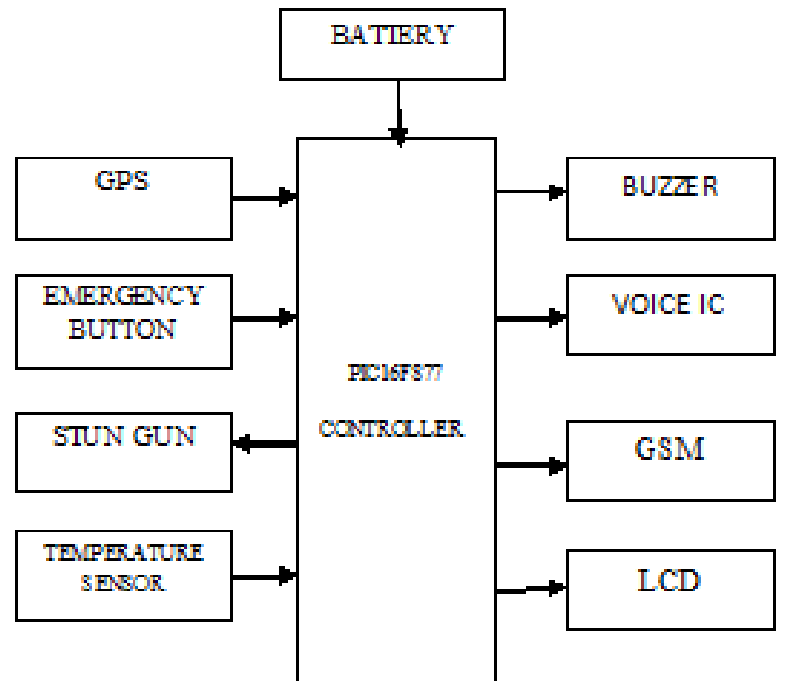

Fig. 1 Block Diagram of the Women Endurance System 
Vol. 8, Issue 6, June 2019

The device now gets triggered and receives location co-ordinates From the GPS receiver transmits these coordinates in the form of SMS to the predefined mobile numbers and starts to record any conversation happening in there . The temperature sensor senses the body temperature of the person who is having the device and also sends that temperature details along with the location coordinates

\section{RESULTS\&DISCUSSIONS}

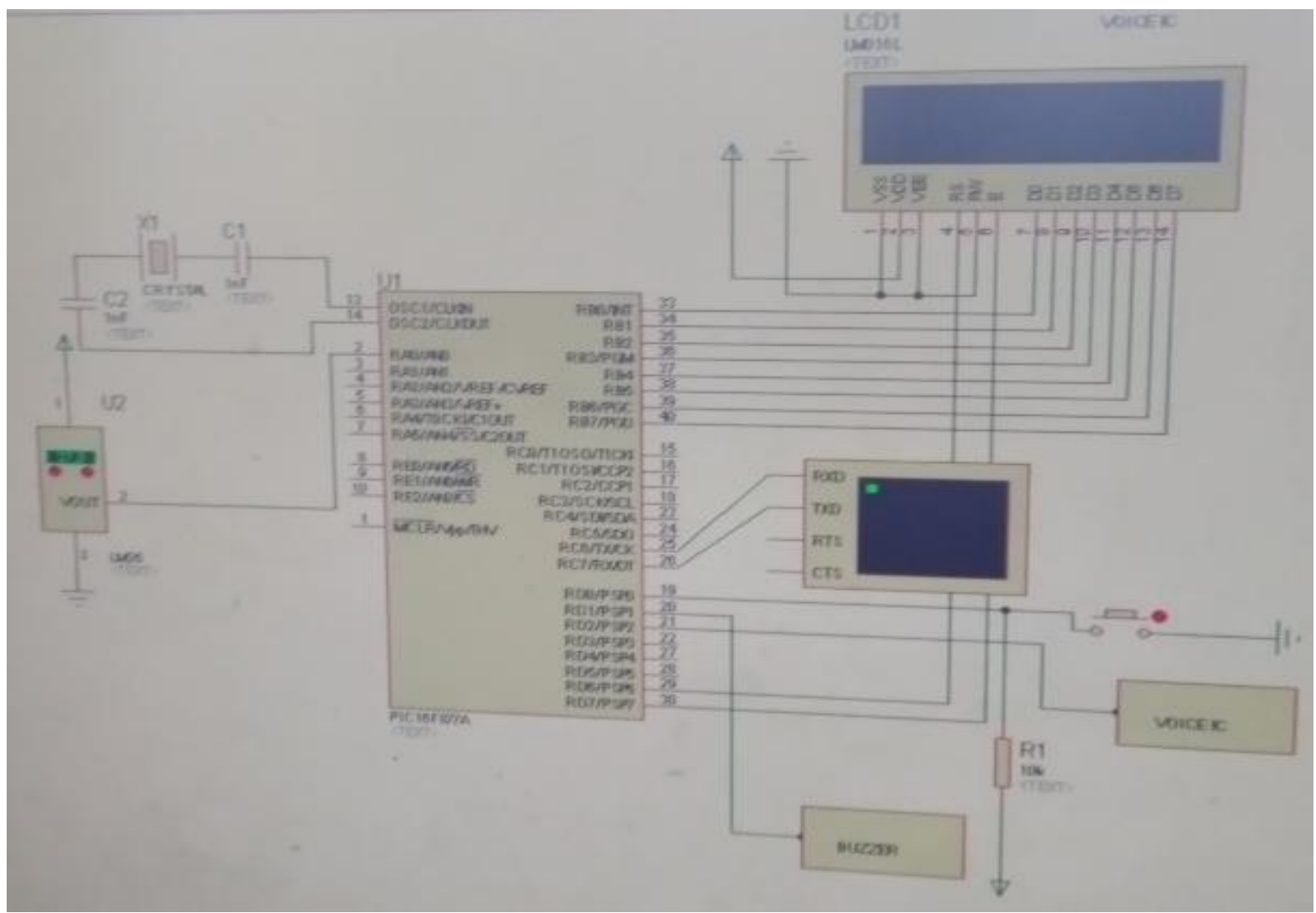

Fig. 2 Simulation Output of Women Endurance System

Our primary goal of this paper is to ensure every woman in our society to feel safe and secured. Implementing a real time application and a device solve the problem to extent, Fig. 2 shows the simulation output of women endurance system, and subsequent hardware modules were connected in the device, Fig. 3 shows Hardware modules of Women Endurance System In order to make the safety this system provides a major solution, through aFig .4 shows the mobile output, women safety endurance system.

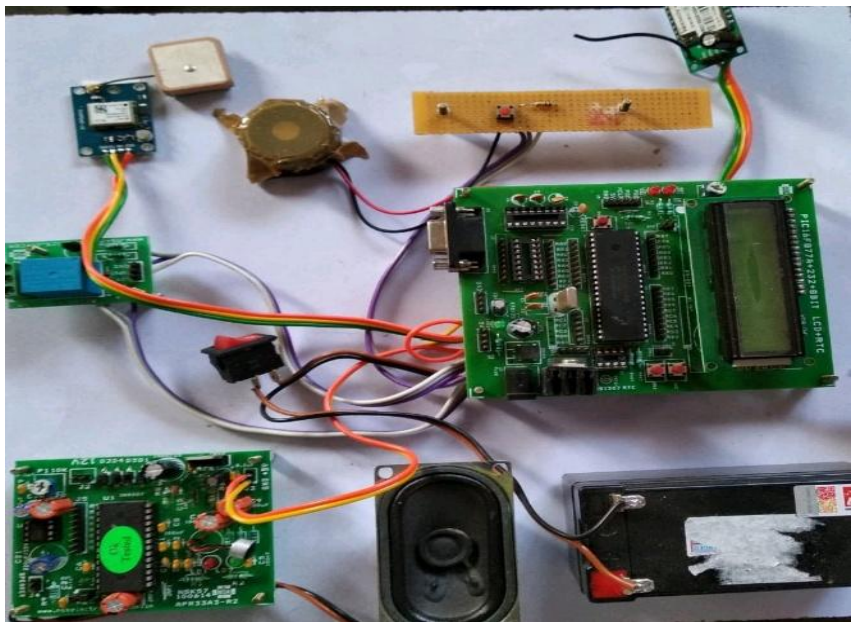

Fig. 3 Hardware modules of Women Endurance System 
Vol. 8, Issue 6, June 2019

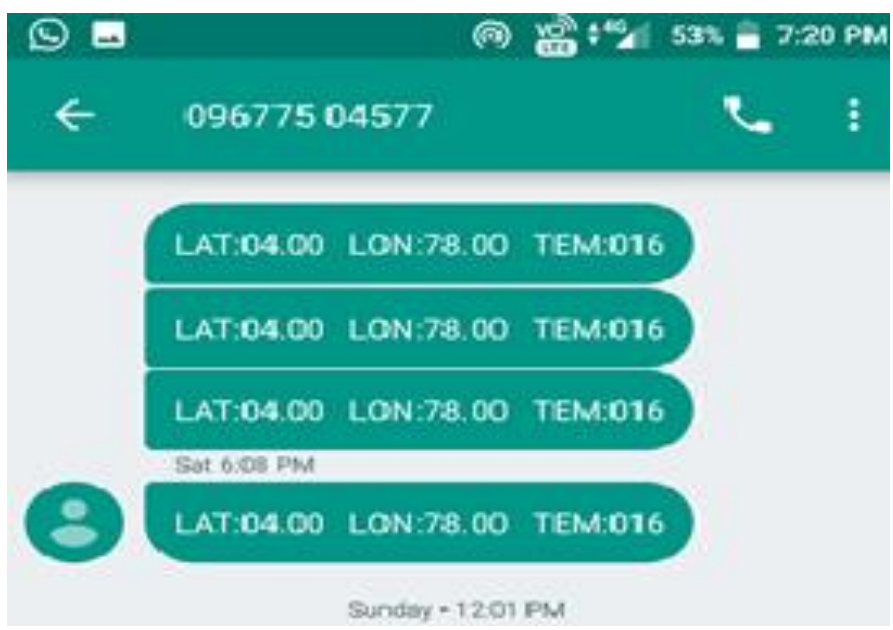

Fig. 4 Mobile interface Output Women Endurance System

\section{CONCLUSION}

According to the survey $85 \%$ of them working women in India. Even now a days womens are facing many hurdles In this paper we have proposed a device that can be used by women in case of emergency situation by just merely a push of a button and it will send the location coordinates to the police and the family members and with further research and innovation this device can be used as small wearable pendant or watches.

\section{REFERENCES}

[1]. Design and implementation of safety armband for women using arm7 by glenson toney, dr. Fathima jabeen, puneeth.

[2]. R.Balamurugan,N.R.Nagarajan "Automatic Robotic Arm Using Hand Gestures”, International journal of Engineering Research \& Technology. Issn: 2278-0181 march 2017.

[3]. R.Balamurugan,N.R.Nagarajan "Smart Method Of Vehicular Tactical Manoeuvre system"International Journal of Advanced Research in Electrical Electronicsand Instrumental Engineering volume 8issue 4 April 2019. ISSN 2320-3765.

[4]. N.R.Nagarajan, R.Balamurugan, “ A DFT Tactic Aimed at Testable Q-flop Rudiments”, International Journal of Advanced Researchin Electrical,Electronicsand Instrumental Engineering volume 8issue 4 April 2019. ISSN 2320-3765

[5]. Protection of the child intelligent GSM and GPS based automatic tacking system by deepak punetha, vartika Mehta.

\section{BIOGRAPHY}

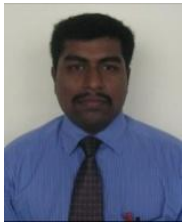

R. Balamurugan, completed Bachelors degree in Electronics and Communication Engineering and Masters VLSI Design from Anna University in 2008 and 2012 respectively. He is lifetime Member of Indian Society of Technical Education (MISTE), and field of research interest is designing Realtime Embedded Systems, IOT, Wireless Communication. He has a teaching experience of 8 years. Presently working as Assistant Professor, ECE Dept. in K. Ramakrishnan College Of Engineering, Trichy. 